\title{
Medical students are not blank slates: Positionality and curriculum interact to develop professional identity
}

\author{
Kirkpatrick B. Fergus $^{1} \cdot$ Bronte Teale $^{2} \cdot$ Milani Sivapragasam $^{3} \cdot$ Omar Mesina $^{1} \cdot$ Erene Stergiopoulos $^{4}$
}

Published online: 5 January 2018

(c) The Author(s) 2018. This article is an open access publication.

As Stubbing et al. [1] have rightly pointed out, medical students do not enter their training as 'blank slates'. We carry with us diverse life experiences, which influence early notions of what it means to be a doctor. As co-authors of this accompanying commentary, and as medical students from universities in the US, Canada, and Australia, we entered medical school with a range of preconceptions of what makes a doctor. In writing this commentary, we have drawn from our varied and unique perspectives, including our respective experiences as members of communities often underrepresented in medicine, including LGBT (lesbian, gay, bisexual and transgender), racialized, disabled, refugee, undocumented, and low socioeconomic status communities. Of course, we do not represent the communities to which we belong, and our composite identities include communities well-represented in medicine. Further, our lived experiences cannot possibly capture the multifarious backgrounds of physicians in training. However, these experiences have been influential in our trajectory-they guided our aspirations to pursue medicine as a career, and at times hindered our pathway to medicine, and continually shape our notion of what it means to be a physician. As a result, this commentary aims to reflect on how diverse medical student positionalities influence professional identity formation. Moreover, we aim to highlight the role of medical education institutions' formal and hidden curricula in empowering students to develop a professional identity that embraces their positionality.

Kirkpatrick B. Fergus

kirk.fergus@ucsf.edu

1 School of Medicine, University of California-San Francisco, San Francisco, CA, USA

2 School of Medicine, Western Sydney University-Campbelltown, Sydney, Australia

3 Faculty of Medicine, McGill University, Montreal, Quebec, Canada

4 Faculty of Medicine, University of Toronto, Toronto, Ontario, Canada

\section{Diversity matters}

Medical schools internationally have embraced a mandate of social accountability, so that medical students may reflect the diverse populations they will serve [2, 3]. However, when these increasingly diverse medical students enter training, they are confronted with pressures to conform to a preset professional identity [4]. These pressures occur both at the level of formal curricular teaching, and through the hidden curriculum - that is, the institutional practices, policies, and language that shape learners' perceptions of their student role [5]. Stubbing et al. rightly describe the learner identity as one important element of early professional identity formation [1]. As medical students, our preconceived 'figured world' is indeed at odds with the reality of medical training for a number of reasons, and supporting medical students through this tension is vital. However, we contend that learners' lived experiences-in particular, the diverse identities we held before medical school-are essential to acknowledge as we develop our professional roles (Fig. 1). To illustrate this, we provide three thematic examples: privilege, stigma, and micro-aggressions.

How we self-identify in relation to privilege impacts our figured preconceptions of medical school. For example, while some students have physician parents or significant exposure to medicine, others enter medical school with limited knowledge about the profession. The social capital disparity is manifest in many communities, such as those of low socioeconomic status, racial and ethnic minorities, and rural upbringings. This disparity lingers throughout medical school, challenging these students' preparedness for academic and clinical endeavours [6, 7]. At the same time, we find compelling what one medical student from an 'underprivileged' background wrote that her unique identity enhanced her ability to practice empathic care and understand the social determinants of health [8].

Learners with marginalized identities may also face significant stigma. For example, medical culture often frames illness as a weakness or failure to cope $[9,10]$. As a result, medical students with disabilities often hesitate to disclose 


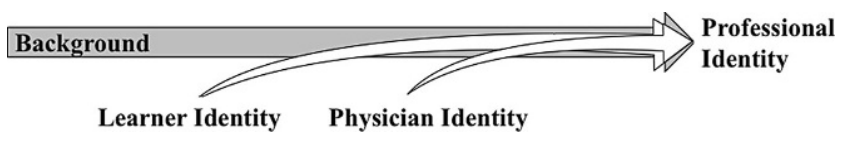

Fig. 1 Integrating past and future: Supporting student backgrounds in professional identity formation

a disability out of fear of being scrutinized by classmates or teachers, or being judged as less competent [11]. Similarly, sexual and gender minorities face stigma, with one study finding that $29.5 \%$ concealed their identity for fear of discrimination [12]. Yet these learners hold valuable perspectives - for example, as recipients of healthcare and as self-advocates-which we translate into our own development as healthcare providers.

Beyond the effects of overt stigma, discrimination and harassment, learners commonly experience everyday slights and micro-aggressions in their educational and clinical placements $[7,13,14]$. In particular, we who identify as racial minorities must navigate this climate daily, which can adversely impact our wellbeing [15]. Our professional identity is fashioned by our sociocultural upbringing in parallel with our medical training, and many of us face the particulars of this 'emotional tension' without adequate support.

\section{Implications for curriculum development}

How then can medical institutions support students to become physicians who honour their lived experiences? While the medical education community is making great efforts to address this issue, we draw on our experiences as students to suggest three key approaches institutions can adopt to better facilitate professional identity formation by meaningfully embracing diversity [16].

\section{Access to student services}

Issues surrounding wellbeing (including discrimination, harassment and mental health) can disproportionately affect students from marginalized backgrounds $[14,17]$. We urge medical institutions to provide appropriate accommodations (e.g. flexibility in scheduling), disability services [18], mental health and counselling services, well-being workshops, and adequate financial support. Making these services available is one component of a greater cultural and structural change aimed at restructuring the hidden curriculum [5].

\section{Near-peer and faculty mentorship}

As the significance of role models in professional identity formation is well established [19], we suggest tailored mentorship programs that increase exposure to role models with similar lived experiences to empower trainees to embrace their unique experiences. This approach is supported by emerging evidence regarding gender disparity in surgery, which suggests that a paucity of same-gender role models prevents women from conceiving of a career in surgery [20, 21]. Mentorship programs for staff have also been identified as an effective way to increase recruitment and retention of underrepresented minorities in medical school faculties [22, 23], which could in turn increase the availability of diverse role models.

\section{Formal curricula}

Formal teaching that acknowledges students' diverse experiences and draws on those experiences as forms of expertise will better prepare all students to treat the diverse populations they serve $[24,25]$. In their work on underrepresented minority medical students, Rumala and Cason [26] illustrate the value of formally collaborating with student minority organizations in improving peer support and recruitment programs. The curriculum, with support from senior leadership in the medical institution, can therefore empower students to value and learn from their diverse positionalities as assets to their professional identity formation [27].

In closing, we are grateful to medical institutions for their efforts to increase diversity in medical school classes. However, the next important step is to support the more personal influences on our 'figured worlds' that bear realworld significance. Empowering students to integrate their pre-medical backgrounds into their developing identity is crucial not only to improving the process of professional identity formation for diverse students, but also to nurturing empathic and insightful physicians uniquely suited to respond to the plights of their patients.

Acknowledgements The authors wish to thank Patricia O'Sullivan and Wendy $\mathrm{Hu}$ for their guidance in the preparation of this manuscript. We are grateful to the editorial staff at Perspectives in Medical Education for valuing the student voice in medical education. We also thank our diverse medical student colleagues who inspire us with their life stories that led them to medicine.

Open Access This article is distributed under the terms of the Creative Commons Attribution 4.0 International License (http:// creativecommons.org/licenses/by/4.0/), which permits unrestricted use, distribution, and reproduction in any medium, provided you give appropriate credit to the original author(s) and the source, provide a link to the Creative Commons license, and indicate if changes were made. 


\section{References}

1. Stubbing E, Helmich E, Cleland J. Authoring the identity of learner before doctor in the figured world of medical school. Perspect Med Educ. 2017;7. https://doi.org/10.1007/s40037-017-0399-0

2. Eva KW. Moving beyond childish notions of fair and equitable. Med Educ. 2015;49:1-3.

3. Razack S, Hodges B, Steinert Y, Maguire M. Seeking inclusion in an exclusive process: discourses of medical school student selection. Med Educ. 2015;49:36-47.

4. Frost HD, Regehr G. "I am a doctor": negotiating the discourses of standardization and diversity in professional identity construction. Acad Med. 2013;88:1570-7.

5. Hafferty FW. Beyond curriculum reform: confronting medicine's hidden curriculum. Acad Med. 1998;73:403-7.

6. Vaughan S, Sanders T, Crossley N, O’Neill P, Wass V. Bridging the gap: the roles of social capital and ethnicity in medical student achievement. Med Educ. 2015;49:114-23.

7. Orom $\mathrm{H}$, Semalulu T, Underwood $\mathrm{W} 3 \mathrm{rd}$. The social and learning environments experienced by underrepresented minority medical students: a narrative review. Acad Med. 2013;88:1765-77.

8. Zhou SY. Underprivilege as privilege. JAMA. 2017;318:705-6.

9. Fox F, Doran NJ, Rodham KJ, Taylor GJ, Harris MF, O'Connor M. Junior doctors' experiences of personal illness: a qualitative study. Med Educ. 2011;45:1251-61.

10. Chew-Graham CA, Rogers A, Yassin N. 'I wouldn't want it on my CV or their records': medical students' experiences of help-seeking for mental health problems. Med Educ. 2003;37:873-80.

11. Meeks LM, Jain NR. The guide to assisting students with disabilities: equal access in health science and professional education. New York: Springer; 2015. p. 240.

12. Mansh M, White W, Gee-Tong L, et al. Sexual and gender minority identity disclosure during undergraduate medical education: "in the closet" in medical school. Acad Med. 2015;90:634-44.

13. Beagan BL. 'Is this worth getting into a big fuss over?' Everyday racism in medical school. Med Educ. 2003;37:852-60.

14. Dhaliwal JS, Crane LA, Valley MA, Lowenstein SR. Student perspectives on the diversity climate at a U.S. medical school: the need for a broader definition of diversity. BMC Res Notes. 2013;6:154.

15. Perry SP, Hardeman R, Burke SE, Cunningham B, Burgess DJ, van Ryn M. The impact of everyday discrimination and racial identity centrality on African American medical student well-being: a report from the medical student CHANGE study. J Racial Ethn Health Disparities. 2016;3:519-26.

16. Cruess RL, Cruess SR, Boudreau JD, Snell L, Steinert Y. A schematic representation of the professional identity formation and socialization of medical students and residents: a guide for medical educators. Acad Med. 2015;90:718-25.

17. Noori S, Blood A, Meleca J, Kennedy V, Sengupta D. Current directions in medical student well-being. Col Med Rev. 2017;1:10-9.

18. Meeks LM, Bisagno J, Jain N, Herzer K. Support students with disabilities in medicine and health care programs. Disabil Compliance High Educ. 2015;21:1-5.

19. Passi V, Johnson N. The impact of positive doctor role modelling. Med Teach. 2016;38:1139-45.
20. Kerr H-L, Armstrong LA, Cade JE. Barriers to becoming a female surgeon and the influence of female surgical role models. Postgrad Med J. 2016;92:576-80.

21. Abelson JS, Chartrand G, Moo T, Moore M, Yeo H. The climb to break the glass ceiling in surgery: trends in women progressing from medical school to surgical training and academic leadership from 1994 to 2015. Am J Surg. 2016;212:566-72.

22. Rodriguez JE, Campbell KM, Fogarty JP, Williams RL. Underrepresented minority faculty in academic medicine: a systematic review of URM faculty development. Fam Med. 2014;46:100-4.

23. Beech BM, Calles-Escandon J, Hairston KG, Langdon SE, LathamSadler BA, Bell RA. Mentoring programs for underrepresented minority faculty in academic medical centers: a systematic review of the literature. Acad Med. 2013;88:10.

24. Saha S, Guiton G, Wimmers PF, Wilkerson L. Student body racial and ethnic composition and diversity-related outcomes in US medical schools. JAMA. 2008;300:1135-45.

25. Niu NN, Syed ZA, Krupat E, Crutcher BN, Pelletier SR, Shields HM. The impact of cross-cultural interactions on medical students' preparedness to care for diverse patients. Acad Med. 2012;87:1530-4.

26. Rumala BB, Cason FD. Recruitment of underrepresented minorities to medical school: minority medical student organisations, an untapped resource. J Natl Med Assoc. 2007;99:1000-9.

27. Marrast L, Zallman L, Woolhandler S, Bor DH, McCormick D. Minority physicians' role in the care of underserved patients: diversifying the physician workforce may be key in addressing health disparities. Jama Intern Med. 2014;174:289-91.

Kirkpatrick B. Fergus is a third-year medical student in the School of Medicine at University of California, San Francisco. His previous work in medical education focuses on learning dashboard development. He serves as a student Curriculum Ambassador and a Coordinator for the Peer Teaching Program at UCSF.

Bronte Teale is a final-year medical student in the School of Medicine at Western Sydney University where she is a member of the Professionalism Working Group. Her current work in medical education explores the relationship between leadership role models, gender, and students' aspirations for medical leadership.

Milani Sivapragasam is a second-year medical student at McGill University where she helped found a Medical Education Committee and led a review of the pre-clerkship curriculum. Milani is particularly interested in how we may cultivate a medical training culture that values inquiry and critical thinking.

Omar Mesina is a second-year medical student in the School of Medicine at University of California, San Francisco. His current work in medical education focuses on the development of structural competency coursework in the preclinical curriculum.

Erene Stergiopoulos MA, is a third-year medical student in the Faculty of Medicine at the University of Toronto and founder of the Medical Student Accessibility Network. Her research examines the experiences of medical trainees with disabilities and effects of the hidden curriculum on their professional identity construction. 